\title{
Influence of phytochemicals in induced psoriasis (Review)
}

\author{
ELENA NICULET ${ }^{1,2^{*}}$, DIANA SABINA RADASCHIN ${ }^{3,4}$, FLORENTINA NASTASE $^{5}$, MIRUNA DRAGANESCU ${ }^{4,6 *}$ \\ LILIANA BAROIU $^{4,6^{*}}$, MAGDALENA MIULESCU ${ }^{1}$, MANUELA ARBUNE $^{4,6}$ and ALIN LAURENTIU TATU ${ }^{3,4,7}$ \\ ${ }^{1}$ Department of Morphological and Functional Sciences, Faculty of Medicine and Pharmacy, \\ 'Dunarea de Jos' University, 800010 Galati; ${ }^{2}$ Department of Pathology, 'Sf. Apostol Andrei’ Emergency \\ Clinical Hospital, 800578 Galati; ${ }^{3}$ Research Center in the Field of Medical and Pharmaceutical Sciences, \\ 'Dunarea de Jos' University; ${ }^{4}$ Clinical Department, Faculty of Medicine and Pharmacy, 'Dunarea de Jos' University, \\ 800010 Galati; ${ }^{5}$ Department of Neuropsychomotor Rehabilitation, 'Sf. Ioan' Emergency Clinical Hospital \\ for Children, 800487 Galati; ${ }^{6}$ First Infectious Diseases Department and ${ }^{7}$ Dermatology Department, \\ 'Sf. Cuvioasa Parascheva' Clinical Hospital of Infectious Diseases, 800179 Galati, Romania
}

Received May 18, 2020; Accepted June 17, 2020

DOI: $10.3892 /$ etm.2020.9013

\begin{abstract}
Cytokines involved in pathogenesis of psoriasis such as interleukins (IL-1 $\beta$, IL-6, IL-17, IL-22, IL-23), interferon- $\alpha$, tumor necrosis factor- $\alpha$ and interferon- $\gamma$ can also become therapeutic targets. Research currently uses murine models of imiquimod-induced psoriatic-type dermatitis in order to analyze potentially helpful phytotherapeutics for psoriasis treatment: Curcuma longa, Aloe vera, Nigella sativa, Rubia cordifolia, Smilax china, Thespesia populnea, Wrightia tinctoria, Scutellaria baicalensis, Cassia tora, Pongamia pinnata and various Chinese herbal formulas. Psoriasis is a chronic inflammatory disease with complex pathogenic mechanisms that yield abnormal immune responses with clinical and morphological echoes (erythematous, scaly plaques with a histopathological basis made up of alterations i.e. keratinocyte aberrant proliferation, parakeratosis or chronic inflammation). The current therapeutic approach has only been able to manage the disease, without ensuring a certified treatment, thus giving rise to the need for better medications. This novel therapeutic approach has shown promising results in preclinical studies, giving hope for future phytochemical animal-based studies.
\end{abstract}

Correspondence to: Dr Diana Sabina Radaschin, Research Center in the Field of Medical and Pharmaceutical Sciences, 'Dunarea de Jos' University, 35 Al. I. Cuza Street, 800010 Galati, Romania

E-mail: dianaradaschin@yahoo.com

Dr Florentina Nastase, Department of Neuropshychomotor Rehabilitation, 'Sf. Ioan' Emergency Clinical Hospital for Children, 2 Gh. Asachi Street, 800487 Galati, Romania

E-mail: florentina34ro@yahoo.com

*Contributed equally

Key words: imiquimod, phytotherapeutics, interleukins, psoriasis, curcumin

\section{Contents}

1. Introduction

2. Literature data

3. Results and Discussion

4. Conclusions

\section{Introduction}

Cytokines that are involved in psoriasis and can represent therapy targets are Interleukins, IL-1 $\beta$, IL-6, IL-17, IL-22 and IL-23 (these form an important and highly targeted inflammatory axis), interferon- $\alpha$, tumor necrosis factor- $\alpha$ (TNF- $\alpha$ ) and interferon- $\gamma$. With a global prevalence of $2-4 \%$, psoriasis is one of the most frequent chronic inflammatory, stress-related diseases with recurrent evolution and consequences concerning the physical and mental well-being of patients. Being a noninfectious but stigmatizing skin disease, psoriasis benefits from the current conventional therapy, which unfortunately does not represent a cure, as it only manages signs and symptoms of the disease. From the 5 types of psoriasis (vulgaris, guttate, intertriginous, pustular and erythrodermic), psoriasis vulgaris is the most common clinical form, while the erythrodermic form is the most severe (1-6).

The pathogenic mechanisms underlying the disease are highly complex, combining several key role-players: Inflammatory cells, cytokines, growth factors and keratinocytes. Inflammatory cells which take part in the development of psoriatic-type dermatitis are $\mathrm{CD}^{+}$and $\mathrm{CD}^{+} \mathrm{T}$ cells, various types of dendritic cells, neutrophils, natural killer $\mathrm{T}$ cells and mast cells; keratinocytes participate in the inflammatory process through their surface cytokine receptors. Abnormal immune response triggers keratinocyte hyperproliferation translated clinically through irregular, erythematous, scaly plaques, characterized morphologically by parakeratosis, acanthosis, Munro's microabscesses, dermal inflammatory cells and congestive blood vessels.

The current therapeutic approach is only managing the disease, not curing it, psoriasis having a life-long recurrent 
episodic evolution (7-14). Psoriasis patients, females in particular, are at risk of aggravating the disease or at risk for adverse reactions from substances used in cosmetic procedures such as dermal filler treatment with (reticulated) hyaluronic acid or hyperpigmentation treatment with trichloroacetic acid, which could aggravate the disease (15-19). Treating physicians have a relatively wide range of therapeutic approaches for psoriasis: From a large number of topicals, to nonbiologic and biologic systemic medications, to phototherapy. Each patient has a personalized treatment plan in concordance with the severity of the disease, the patient's comorbidities and least, but not last, its compliance. The exogenous type of therapies includes vitamin D derivatives, topical steroids, retinoids or UV therapy; systemic therapy encompasses anti-inflammatory drugs, methotrexate, cyclosporine, and biologics such as secukinumab, adalimumab or ustekinumab. The increase in efficacy and safety standards concerning the aforementioned therapies does not guarantee their success, affordability or patient compliance (20-25).

\section{Literature data}

Current research concerning psoriasis, selected from 2008 until 2019 , has based itself on preclinical models of experimental mice by inducing psoriasis-type dermatitis to murine models (knockout mice, transgenic mice) with the help of imiquimod 5\% used in the treatment of actinic keratosis or basal cell carcinoma. Imiquimod is an imidazoquinoline amine, a Toll-like receptor TLR7/TLR8 ligand and an agent with local immunomodulatory properties which by topical applications induces psoriatic-type dermatitis both clinically and morphologically. These applications also have a more general effect by elevating the levels of inflammatory cells and subsequently the level of cytokines that they produce; through these actions, murine models with imiquimod-induced psoriasis become ideal for studying the efficacy of herbal therapeutics on psoriasis $(26,27)$.

Because it affects mainly the skin and due to the fact that it is a life-long disease, psoriasis generates high levels of distress and it has many associated psychiatric disorders, such as anxiety and depression. There is a clear necessity for therapies and medicines which offer relief for longer periods of time or which can effectively cure it. The acute requisite for innovative therapies stems also from the fact that the current ones have many side-effects including skin atrophy, sensitivity to solar light, skin irritations, high risk for infection, carcinogenesis, immune system suppression and organ toxicity (28-30). Patients could benefit from these phytotherapeutics through their low costs, low number of adverse effects and multiple biochemical activities, thus improving the overall patient compliance.

\section{Results and Discussion}

Western researchers have turned their focus to the east: in recent years there have been intense investigations made concerning Chinese medicine and other herbal remedies.

Curcuma longa. Turmeric/Curcuma longa is a non-toxic, perennial rhizomatous plant with many medicinal properties, including anti-inflammatory, anticarcinogenic, antioxidant, antimicrobial and wound-healing. This South-East Asian herb is part of the Zingiberaceae family (ginger family) and has been used in traditional Chinese medicine for centuries (for respiratory and cardiovascular diseases, liver or gastrointestinal ones or arthritis), having more than one hundred active components, of which turmeric being the most important one. The cellular background for the inhibition of inflammation and that of keratinocyte abnormal proliferation resides on nuclear factor- $\kappa \mathrm{B}(\mathrm{NF}-\kappa \mathrm{B})$ suppression, TNF- $\alpha$, IL- $1 \beta$ and IL-6 downregulation and inactivation of JNK, p38 MAPK and STAT-3 pathways. It modulates dendritic cells and also reduces the levels of IL-2 and interferon- $\gamma(27,31)$.

Materials and methods used in the studies had common grounds: many used BALB/c mice, had several days of imiquimod $5 \%$ applied on the hairless back skin and ear followed by topical curcumin ointments or gel applications. The evolution and involution of psoriatic lesions were evaluated by the PASI Score, Psoriasis Area and Severity Index which follows the erythema, scales and thickness of the affected skin (26,31-34).

Curcumin is an important agent in the fight against psoriasis through dose-dependent inhibition of pathological changes in psoriasis-type dermatitis. Important attenuation of the intense dynamic processes of hyperkeratosis and acanthosis were observed microscopically, the PASI score showing a parallel clinical curve of the skin changes. By immunohistochemistry, the infiltrate of $\mathrm{CD} 8^{+} \mathrm{T}$ cells were reduced in the group of experimental mice treated with Curcuma longa extract. Also, through Western blot and immunohistochemical methods the inflammatory signaling pathways, JNK, p38 MAPK and STAT-3 were suppressed by the herbal extract $(27,31,35-38)$.

The same imiquimod-induced psoriasis murine model was used in another preclinical trial with the help of curcumin-loaded ethosomes (which enhance the local and transdermal delivery of the needed drug). It was demonstrated that Curcuma longa is a viable treatment for psoriasis through the inhibition of cytokines such as IL-17A, IL-17F and other inflammatory factors (TNF- $\alpha$ ); this translated clinically as lower PASI scores (reflected by reduced skin erythema and desquamation) (32).

A study which involved a small number of Indian phytotherapeutics, one of which was curcumin, used the stem and from this an aqueous extract was made. The group treated with topical curcumin (combined with Aloe vera as local applications) showed an important reduction in skin thickness and inflammatory infiltrate by reducing the levels of TNF- $\alpha$, IL- 6 and IL-1 $\beta$, decreasing neutrophil infiltration and by inhibiting the STAT-3 pathway, and therefore it is necessary for us to study the interference with skin microbioma in future studies $(33,39-41)$.

Aloe vera. One of the most commonly used medicinal plants, Aloe vera, part of the Liliaceae family, is well known for its antiseptic, anti-inflammatory, wound-healing and antidiabetic properties, its immune system enhancing properties, and many others such as high density lipoprotein enhancer, antiallergenic bioproperties through its numerous bioactive components $(>200)$. This compound has been widely used in clinical trials, with promising antipsoriatic effects. A preclinical study on a mouse tail model of psoriasis used an ethanolic extract of Aloe vera gel which had significant positive effects on psoriatic 
skin (differentiation with orthokeratosis), comparable to those of tazarotene applications (42-44).

\section{Other experimental formulas and phytotherapeutics}

PSORI-CM01 and PSORI-CM02. PSORI-CM01 is the basis of the second formula and it has been proven through animal studies to have antipsoriatic properties by inducing autophagy and inhibiting the cytokines and chemokines involved in psoriasis $(34,45)$.

PSORI-CM02 is a medicinal formula which encompasses five different plants that are frequently used in China: Curcuma longa, Paeoniae radix rubra, Smilax glabra and Sarcandrae herba. PSORI-CM02 had no side effects in a study on BALB/c mice and it improved murine body mass (an important indicator for overall health and for imiquimod induced inflammation). This formula has immunomodulatory properties by reducing the $\mathrm{T}$ cell infiltrate, lowering the levels of interferon- $\gamma$, IL-17A and increasing the levels of IL-4, an anti-inflammatory agent, GATA3 pathway is an important therapeutic target (34).

Other studies focused on extracts obtained from different herbs with pharmacological properties: Nigella sativa, Rubia cordifolia, Smilax china, Thespesia populne, Wrightia tinctoria, Scutellaria baicalensis, Piperum nigrum, Komboucha, basil, propolis and other natural extracts used for complementary and alternative anti-psoriatic medicine products targeted against other skin disorders such as lichen planus, lichen sclerosus or other immune associated disorders are key factors in recent research studies (46-55). Mouse-tail experimental models were used and observations were made that all of these plants reduced epidermal acanthosis, they promoted normal epidermal differentiation with ortokeratin formation and they also had significant antipsoriatic properties, as compared with control groups. Kigelia africana used as a methanol extract-based ointment had increased orthokeratosis and reduced epidermal thickness dose-dependenty. Cassia tora and Pongamia pinnata extracts had significant effects by decreasing epidermal thickness and maintaining a normal stratum granulosum (56).

\section{Conclusions}

Herbal therapeutics are part of the novel approach to current medicinal therapy having established evidence by extensive research that supports their use through the many bioproperties that they possess. Although preclinical studies with murine models of induced psoriasis are highly necessary in identifying and selecting herbal therapeutics with anti-psoriatic properties, further clinical studies are imperative for them to be used globally by patients. The surge in phytotherapeutic research is a direct response to the need for better psoriasis treatments without adverse effects.

\section{Acknowledgements}

Not applicable.

\section{Funding}

No funding was received.

\section{Availability of data and materials}

The information generated and analyzed during the current study is available from the corresponding author on reasonable request.

\section{Authors' contributions}

EN, LB, MM, MA and ALT were involved in the conception of the study and had major contribution in the writing and revising of the manuscript. DSR, FN and MD assisted in the acquisition, analysis and interpretation of the data. All authors read and approved the final manuscript.

\section{Ethics approval and consent to participate}

Not applicable.

\section{Patient consent for publication}

Not applicable.

\section{Competing interests}

The authors declare that they have no competing interests.

\section{References}

1. Shawahna R and Jaradat NA: Ethnopharmacological survey of medicinal plants used by patients with psoriasis in the West Bank of Palestine. BMC Complement Altern Med 17: 4-13, 2017.

2. Yang L, Zhang CS, May B, Yu J, Guo X, Zhang AL, Xue CC and Lu C: Efficacy of combining oral Chinese herbal medicine and NB-UVB in treating psoriasis vulgaris: A systematic review and meta-analysis. Chin Med 10: 27-41, 2015.

3. Meng S, Lin Z, Wang Y, Wang Z, Li P and Zheng Y: Psoriasis therapy by Chinese medicine and modern agents. Chin Med 13: 16-26, 2018.

4. Grigore O, Mihailescu AI, Solomon I, Boda D and Caruntu C: Role of stress in modulation of skin neurogenic inflammation. Exp Ther Med 17: 997-1003, 2019.

5. Ilie MA, Caruntu C, Lixandru D, Tampa M, Georgescu SR, Constantin MM, Constantin C, Neagu M, Zurac SA and Boda D: In vivo confocal laser scanning microscopy imaging of skin inflammation: Clinical applications and research directions. Exp Ther Med 17: 1004-1011, 2019.

6. Caruntu C, Boda D, Caruntu A, Rotaru M, Baderca F and Zurac S: In vivo imaging techniques for psoriatic lesions. Rom J Morphol Embryol 55: (Suppl 3) 1191-1196, 2014.

7. Chiricozzi A, Romanelli P, Volpe E, Borsellino G and Romanelli M: Scanning the immunopathogenesis of psoriasis. Int J Mol Sci 19: 179-210, 2018.

8. Özkesici-Kurt B, Donmez L, Nazlim B, Bozkurt S, AkmanKarakas A, Yilmaz E and Alpsoy E: Defining the natural course of psoriasis: A single-center cohort study of 100 patients. Turk J Dermatol 12: 33-37, 2018.

9. Hsu PY, Yen HH, Yang TH and Su CC: Tetrathiomolybdate, a copper chelator inhibited imiquimod-induced skin inflammation in mice. J Dermatol Sci 92: 30-37, 2018.

10. Rozis G, Benlahrech A, Duraisingham S, Gotch F and Patterson S: Human Langerhans' cells and dermal-type dendritic cells generated from CD34 stem cells express different toll-like receptors and secrete different cytokines in response to toll-like receptor ligands. Immunology 124: 329-338, 2008.

11. Negrei C, Arsene AL, Toderescu CD, Boda D and Ilie M: Acitretin treatment may influence the cell membrane fluidity. Farmacia 60: 767-772, 2012.

12. Batani A, Brănișteanu DE, Ilie MA, Boda D, Ianosi S, Ianosi G and Caruntu C: Assessment of dermal papillary and microvascular parameters in psoriasis vulgaris using in vivo reflectance confocal microscopy. Exp Ther Med 15: 1241-1246, 2018. 
13. Fekete GL, Cotoi OS and Fekete JE: Multiple nodular cutaneous metastases as the first clinical sign of signet ring cell gastric carcinoma: Case report. Acta Dermatovenerol Croat 20: 34-37, 2012.

14. Fekete GL and Fekete L: Cutaneous leukocytoclastic vasculitis associated with erlotinib treatment: A case report and review of the literature. Exp Ther Med 17: 1128-1131, 2019.

15. Rendon MI, Berson DS, Cohen JL, Roberts WE, Starker I and Wang B: Evidence and considerations in the application of chemical peels in skin disorders and aesthetic resurfacing. J Clin Aesthet Dermatol 3: 32-43, 2010.

16. Ardeleanu V, Berbece SI, Florescu IP and Jecan RC: The use of hyaluronic acid combined with teosyal redensity II for the treatment of dark circles under the eyes. Mater Plast 54: 37-40, 2017.

17. Jecan RC, Nicolau A, Florescu IP, Ardeleanu V and Berbece S: Use of trichloroacetic acid in treating facial hyperpigmentation. Mater Plast 54: 88-90, 2017.

18. Ardeleanu V, Dobre M and Georgescu EM: Deep facial wrinkle treatment outcome after first injection of reticulated hyaluronic acid. Rev Chim (Bucharest) 66: 2129-2131, 2015.

19. De Boulle K and Heydenrych I: Patient factors influencing dermal filler complications: Prevention, assessment, and treatment. Clin Cosmet Investig Dermatol 8: 205-214, 2015.

20. Bridgman AC and Kirchhof MG: Treatment of psoriasis vulgaris using low-dose naltrexone. JAAD Case Rep 4: 827-829, 2018.

21. Schadler ED, Ortel B and Mehlis SL: Biologics for the primary care physician: Review and treatment of psoriasis. Dis Mon 65: 51-90, 2019.

22. Brănisteanu DE, Voicu CM, Creţu A, Dimitriu A, Luca MC and Sălăvăstru CM: Adverse reactions of biological therapy for psoriasis. Rev Med Chir Soc Med Nat Iasi 119: 38-44, 2015.

23. Negrei C, Ginghină O, Caruntu C, Burcea Dragomiroiu G and Jinescu G and Boda D: Investigation relevance of methotrexate polyglutamates in biological systems by high performance liquid chromatography. Rev Chim (Bucharest) 66: 766-768, 2015.

24. Negrei C, Caruntu C, Ginghina O, Dragomiroiu GT, Toderescu CD and Boda D: Qualitative and quantitative determination of methotrexate polyglutamates in erythrocytes by high performance liquid chromatography. Rev Chim (Bucharest) 66: 607-610, 2015.

25. Boda D, Negrei C, Nicolescu F and Badalau C: Assessment of some oxidative stress parameters in methotrexate treated psoriasis patients. Farmacia 62: 704-710, 2014.

26. Li Y, Zhang G, Chen M, Tong M, Zhao M, Tang F, Xiao R and Wen H: Rutaecarpine inhibited imiquimod-induced psoriasis-like dermatitis via inhibiting the NF- $\mathrm{BB}$ and TLR7 pathways in mice. Biomed Pharmacother 109: 1876-1883, 2019.

27. Varma SR, Sivaprakasam TO, Mishra A, Prabhu S, Rafiq M and Rangesh P: Imiquimod-induced psoriasis-like inflammation in differentiated human keratinocytes: Its evaluation using curcumin. Eur J Pharmacol 813: 33-41, 2017.

28. Tatu AL, Ionescu MA and Nwabudike LC: Contact allergy to topical mometasonefuroate confirmed by rechallenge and patch test. Am J Ther 25: e497-e498, 2018.

29. Nwabudike LC and Tatu AL: Response to - Chronic exposure to tetracyclines and subsequent diagnosis for non-melanoma skin cancer in a large Mid-Western US population. J Eur Acad Dermatol Venereol 32: e159, 2018.

30. Brănișteanu DE, Ianoşi SL, Dimitriu A, Stoleriu G, Oanţă A and Brănisteanu DC: Drug-induced Rowell syndrome, a rare and difficult to manage disease: A case report. Exp Ther Med 15: 785-788, 2018

31. Li YL, Du ZY, Li PH, Yan L, Zhou W, Tang YD, Liu GR, Fang YX, Zhang K, Dong CZ, et al: Aromatic-turmerone ameliorates imiquimod-induced psoriasis-like inflammation of BALB/c mice. Int Immunopharmacol 64: 319-325, 2018.

32. Zhang Y, Xia Q, Li Y, He Z, Li Z, Guo T, Wu Z and Feng N: CD44 assists the topical anti-psoriatic efficacy of curcumin-loaded hyaluronan-modified ethosomes: A new strategy for clustering drug in inflammatory skin. Theranostics 9: 48-64, 2019.

33. Arora N, ShahK and Pandey-Rai S: Inhibition of imiquimod-induced psoriasis-like dermatitis in mice by herbal extracts from some Indian medicinal plants. Protoplasma 253: 503-515, 2016.

34. Wu DH, Zhang MM, Li N, Li X, Cai QW, Yu WL, Liu LP, Zhu W and Lu CJ: PSORI-CM02 alleviates IMQ-induced mouse dermatitis via differentially regulating pro- and anti-inflammatory cytokines targeting of Th2 specific transcript factor GATA3. Biomed Pharmacother 110: 265-274, 2019.

35. Hosseini A and Hosseinzadeh H: Antidotal or protective effects of Curcuma longa (turmeric) and its active ingredient, curcumin against natural and chemical toxicities: A review. Biomed Pharmacother 99: 411-421, 2018.
36. Valizadeh Kiamahalleh M, Najafpour-Darzi G, Rahimnejad M, Moghadamnia AA and Valizadeh Kiamahalleh M: High performance curcumin subcritical water extraction from turmeric (Curcuma longa L.). J Chromatogr B Analyt Technol Biomed Life Sci 1022: 191-198, 2016.

37. Tasneem S, Liu B, Li B, Choudhary MI and Wang W: Molecular pharmacology of inflammation: Medicinal plants as anti-inflammatory agents. Pharmacol Res 139: 126-140, 2019.

38. Mahomoodally MF, Protab K and Aumeeruddy MZ: Medicinal plants brought by Indian indentured immigrants: A comparative review of ethnopharmacological uses between Mauritius and India. J Ethnopharmacol 234: 245-289, 2019.

39. Tatu AL and Cristea VC: Unilateral blepharitis with fine follicular scaling. J Cutan Med Surg 21: 442, 2017.

40. Gheorghe I, Tatu AL, Lupu I, Thamer O, Cotar AI, Pircalabioru GG, Popa M, Cristea VC, Lazar V and Chifiriuc MC: Molecular characterization of virulence and resistance features in Staphylococcus aureus clinical strains isolated from cutaneous lesions in patients with drug adverse reactions. Rom Biotechnol Lett 22: 12321-12327, 2017.

41. Kubiak K, Sielawa H, Chen W and Dzika E: Endosymbiosis and its significance in dermatology. J Eur Acad Dermatol Venereol 32: 347-354, 2018

42. Kar SK and Bera TK: Phytochemical constituents of Aloe vera and their multifunctional properties: A comprehensive review. Int J Pharm Sci Res 9: 1416-1423, 2018.

43. El-Gammal A, Nardo VD, Daaboul F, Tchernev G, Wollina U, Lotti J and Lotti T: Is there a place for local natural treatment of psoriasis? Open Access Maced J Med Sci 6: 839-842, 2018.

44. Dhanabal SP, Priyanka Dwarampudi L, Muruganantham N, Vadivelan R and Vadivelan R: Evaluation of the antipsoriatic activity of Aloe vera leaf extract using a mouse tail model of psoriasis. Phytother Res 26: 617-619, 2012.

45. Yue L, Ailin W, Jinwei Z, Leng L, Jianan W, Li L, Haiming C, Ling $\mathrm{H}$ and Chuanjian L: PSORI-CM02 ameliorates psoriasis in vivo and in vitro by inducing autophagy via inhibition of the PI3K/Akt/mTOR pathway. Phy tomedicine 64: 153054, 2019.

46. Mihăilă B, Dinică RM, Tatu AL and Buzia OD: New insights in vitiligo treatments using bioactive compounds from Piper nigrum. Exp Ther Med 17: 1039-1044, 2019.

47. Buzia OD, Fasie V, Mardare N, Diaconu C, Gurau G and Tatu AL: Formulation, preparation, physico-chimical analysis, microbiological peculiarities and therapeutic challenges of extractive solution of Kombucha. Rev Chim (Bucharest) 69: 720-724, 2018.

48. Tatu AL and Ionescu MA: Multiple autoimmune syndrome type III thyroiditis, vitiligo and alopecia areata. Acta Endocrinol (Buchar) 13: 124-125, 2017.

49. Brănisteanu DE, Pintilie A, Andres LE, Dimitriu A, Oanță A, Stoleriu $\mathrm{G}$ and Brănişteanu DC: Ethiopatogenic hypotheses in lichen planus. Rev Med Chir Soc Med Nat Iasi 120: 760-767, 2016.

50. Niculet E, Neculia GV, Tatu AL and Buzia OD: Curcuminextraction, physical and chemical analysis, formulas and control. Basic methods for further research. Mater Plast 55: 672-675, 2018.

51. Buzia OD, Mardare N, Dragomir R, Miulescu M and Tatu AL: Pharmaceutical forms with basil and propolis to the benefit of the oral cavity, formulation, preparation and microbiological analysis. Rev Chim (Bucharest) 70: 343-349, 2019.

52. Branisteanu DE, Pintilie A, Dimitriu A, Cerbu A, Ciobanu D, Oanta A and Tatu AL: Clinical, laboratory and therapeutic profile of lichen planus. Rev Med Chir Soc Med Nat Iasi 121: 25-32, 2017

53. Tatu AL and Nwabudike LC: The treatment options of male genital lichen sclerosus et atrophicus short title for a running head: Treatments of genital lichen sclerosus. In: Proceedings of the 14th National Congress of Urogynecology and the National Conference of the Romanian Association for the Study of Pain,pp262-264,2017.

54. Nwabudike LC and Tatu AL: Using complementary and alternative medicine for the treatment of psoriasis: A step in the right direction. JAMA Dermatol 155: 636-637, 2019.

55. Brănişteanu DE, Brănişteanu DC, Stoleriu G, Ferariu D, Voicu CM, Stoica LE, Căruntu C, Boda D, Filip-Ciubotaru FM, Dimitriu A, et al: Histopathological and clinical traps in lichen sclerosus: A case report. Rom J Morphol Embryol 57 (Suppl 2): 817-823, 2016.

56. Herman A and Herman AP: Topically used herbal products for the treatment of psoriasis - mechanism of action, drug delivery, clinical studies. Planta Med 82: 1447-1455, 2016. 